\title{
TYPES OF STUDENTS' SELF-STUDY ACTIVITY IN FOREIGN LANGUAGE CLASSES IN HIGHER SCHOOL
}

\author{
E. Dorofeeva
}

Assoc. Prof. Dr., Kazan Federal University, Russian Federation, elena.dor@mail.ru

\begin{abstract}
The research presents the types of students' self-study, which is defined asindependent and individual work, in foreign language classes, describes and analyzes the types of self-study,independent and individual work, explores the features and effectiveness of the application of this type of activity in classes to improve the quality of education and acquire a fluent level of foreign language speaking, as well as the issue of the necessityto control the self-study, independent and individual work,by a teacher and self-control by students themselves. Acquiring a foreign language is the utmost importance at the current stage of our society development. It is also noted that every year the young generation has a growing interest in learning foreign languages and obtaining a deeper knowledge in this area.In higher education institutions, this becomes possible in classes and as a result of self-study tasks as well. The purpose of this article is to define the concept of self-study, independent and individual work, to study the features and types of self-study activities, to present the tasks (assignments) for students aimed at complex and effective acquisition of language knowledge, contributing to a significant increase in the level of foreign language skills, as well as to consider ways and methods to control the performance of students' self-study, independent and individual work. The objectives of the article are to consider and analyze the types of self-study activities in foreign language classes in higher education institutions, to identify the most appropriate and productive types of individual work of students to obtain deeper language knowledge, as well as to identify criteria for the effectiveness of arranging their self-study, independent and individual work, in foreign language classes in higher education institutions, to pay attention to control over the performance of tasks in the course of selfstudy by the teacher and self-monitoring by the students themselves. The author presents the examples of self-study and individual work assignments being used in foreign language classes at the university in the course of extracurricular self-study. The ideas behind the article can be used to develop basic pedagogical principles for the application of tasks in students' self-study, independent and individual work,in foreign language classes and to develop various types and instructions to use these tasks, taking into account the level of foreign language skills.
\end{abstract}

Keywords:self-study, independent and individual work, types of self-study work/activity, foreign language, students, criteria, assignments, tasks, control, assessment, self-control

\section{INTRODUCTION}

Due to development of the modern society and the expansion of relations with foreign partners, there is a thirst foraccomplished specialists with a high level of foreign language skills. And higher education institutions now face the task to provide students with good knowledge of a foreign language which is taughtapplying effective, optimal forms and methods of teaching, aimed at developing their need for 
continuous self-study, self-improvement and self-development.

In higher education institutions, it is now possible to acquire foreign languages both in classes and effectively organizing extra-curricularself-study and skillfully combined different types and forms of activities for students. Taking this fact into account, the content of curricula in higher education institutions shows a significant increase in the number of hours devoted to independent work of students.

Effectively arranged individual self-study work contributes to the formation of professional competence, and provides the process of developing methodological maturity, skills for self-organization and self-control of educational activities as well. This is extremely important since it implies the formation of a future specialist as an expert of professional activity capable of self-development, designing and transforming his or her actions [3].

The following criteria can be used to effectively arrange students' self-study, independent, work:

- The content of self-study, independent, activity should be related to the formation of competencies;

- The self-study activity should be purposeful, controlled by both students and teachers;

- the assignments are differentiated and variable, i.e. they take into account the individual capabilities, abilities, needs and interests of students;

- The use of a credit system, which includes an accumulative system for assessing students' self-study activity

- Providing students with information methodical means and materials [2, p.114].

\section{METHODS}

The following methods were used in the research: 1. the theoretical methods which are related to the literature searches, namely, such methods as compilation of the bibliography. It is the list of the references which have been chosen according to the researched problem. The next one is abstracting that is a concise text of the main content of one or several studies in general subjects. Summarizing is taking of more detailed records the basis of which is to sum up the main ideas and cases of research. Annotating is a short record of the general contents of a book or an article. Citing is a literal record of expressions which are actual or digital data given in the reference. 2. Theoretical analysis is highlighting and reviewing of specific features, characteristics of the phenomena. Having analyzed definite facts, classified and systematized them, we have revealed general and special features in them, set a general principle or rule. The analysis was followed by synthesis that helped to understand the subject matter of the phenomena studied. 3 . The inductive and deductive methods are logical methods of generalization of the empirical data obtained. Due to the inductive method we have assumed the conception progress from the private opinions to the general output and from a general opinion to a personal conclusion by means of the deductive method. 4. A comparative method allowed us to set similarities and differences between objects and the phenomena. 5. Analysis and synthesis. The analysis has let to clarify which parts the studied object consists of and synthesis has let to connect the parts received when analyzing into integral. As a result, there was a connection of knowledge gained while analyzing in a single system. 6 . Research and synthesis of pedagogical experience of teachers at higher education institutions and teachers of schools directed to the analysis of a status of practice, developing of the best practices.

\section{RESULTS}

In teaching practice, the issues of learners' self-study work have been studied quite deeply. Various researchers interprete it as: 1) the method of teaching (N.V. Kuzmina); 2) the method of learning (G.P. Gerasimov, A.F. Solovyov, etc.); 3) the form of organization of learning activity (V.I. Andreev, B.P. Esipov); 4) the type of learning activity (T.A. llyina); 5) the means of organization and performance of learning activity, etc..

We hold to the point of some authors' view who tend to call self-study work as a form of organization of students' educational activity, carried out by the students according to the teacher's task. The teacher organized and controlled the students' work which is mainly or completely and independently being fulfilled by students without the direct and constant assistance within the limited time [1, p.192].

At the same time, the purpose of self-study learning for us is the development of students' knowledge, skills and abilities in speaking foreign language, as well as their personal qualities, namely, cognitive processes (feeling, perception, attention, memory, thinking, imagination); cognitive abilities (observation, 
purposefulness, curiosity); character traits (self-criticism, perseverance, accuracy, restraint), etc.

The scientific literature presents a great variety of different classification of self-study work. On the basis of our research, all these forms can be distributed in relation to the grounds for classification as follows:

1) Place of work (self-study in the class and out-of-class);

2) Time mode (at a convenient time for the students, consultation);

3) Form of assignments (for recognition, choice, perception, creative tasks);

4) Place in the learning studying/review, comprehension, application, observation, analysis);

5) Involving of students (frontal (when all the students do the same activity) self-study work, group, individual);

6) Sources of knowledge acquisition (self-study/independent work with textbooks, scientific literature);

7) Sources of knowledge (1. word (book, monograph, magazine, Internet, reference books); 2. subjects of reality and their images (during the lecture); 3. students' experience (observations, reporting, writing descriptions, experimental work);

8. Conditions of organization (1. student's planning of classwork under the teacher's direction and control; 2 . Selfstudy when studying out of school which is planned and organized by the student with the teacher's methodological assistance and control);

9. Terms of the work performing (obligatory self-study work, extra work);

10) Phases of implementation (planning and organization; direct implementation, summarizing);

11) Stages of development of the cognitive process (1. means of obtaining new knowledge; 2 . way of forming skills; 3 . way of controlling the results of learning).

Having carefully studied and analyzed the features of various classifications, types and forms of self-study, independent, work, we have decided to divide all self-study activity into in and out of classwork being used in foreign language classes in higher education institutions. These two types of self-study activity can be used as collective, group, individual independent works, as well as reproductive, research and creative. Such a combination of different types of this self-study work helps us, from our point of view, to develop various practices of students, to form their creative thinking.

Examples of self-study in foreign language classes are: working with educational literature, didactic materials, problem solving, doing exercises and tasks, working with various task cards. During a lecture it can be active listening and writing down the lecture, listening to the teacher's explanations and stories; during seminars, conferences, projects these are reports, messages, discussions, conversations, as well as active thinking during a conversation, asking questions and answering them, writing down the most important points; during competitions, for example, using handouts, visual materials, solving crossword puzzles, puzzles, and questions-jokes; roleplaying games.

The examples of extracurricular self-study work can be self-studying of the given literature in the context of the lecture while home reading of this lecture; preparation for seminars, conferences, projects which includes selfstudy of educational literature on the topic proposed by the teacher, reading and learning sources, self-finding and outlining additional sources, preparation and writing of reports, messages, speeches, design of the results of the work (for example, a project), doing creative tasks.

The student may work alone, together with a small group of students, with a friend, or participate in the group activity in a foreign language class. Depending on how the student's activities are organized, both classroom and extracurricular self-study may be in forms of frontal, individual, group or collective in language classes.

Classwork in foreign language workshopscalls for the organization of cognitive activities simultaneously with all the students. For this purpose, we use frontal conversation or independent work performed in the class under the teacher's direct supervision and guidance, where all students do a common assignment. The teacher gives general explanations how to do the task, common techniques of organization. Directs and monitors students' actions, for example, self-reading of the text and highlighting the main idea or listening to the teacher's story in order to understand what has been said, and so on.

Examples of collective self-study, independent, work in foreign language classes are: joint preparation and design of the project, newspapers, dramatization/plays (sketches, dialogues, fairy tales), etc.

Group self-study work can include: work of students in pairs, the division of the group into subgroups, etc. The 
following are examples of group independent work in foreign language classes: joint preparation and design of the project, newspapers, dramatization (skits, dialogues, fairy tales), etc.

Despite the fact that students receive a common task, general instruction, everyone works independently, individually, strives to achieve the goal, primarily through their own efforts. Thus, in foreign language classes, a combination of collective and individual work is achieved when all students, rather than individual students, are involved. Examples of such individual work are: performing individual tasks, preparing reports, speeches, etc.

In foreign language classes, as it has been mentioned earlier, it is necessary to combine frontal, collective, group and individual forms of self-study, independent work, which contributes to the effectiveness of learning.

In addition to the above types of self-study, independent work, it is impossible to do without research and creative work in foreign language classes in higher education institutions.

Reproductive self-study, independent, activities imply the reproduction or repetition of previously created methods of action. Examples of reproductive independent work are: abstract and listening to a lecture, repetitions in plays, etc.

In the foreign language classes at university, we consider that we can effectively combine reproductive and creative self-study, independent work to increase the students'activity and independence. In this combination, in our opinion, students are taught to think and acquire knowledge, skills and abilities in the most effective way.

The creative self-study can presented by drafting reports, messages, preparation and projects, newspaper design, staging, sounding of video films, preparation and participation in concerts, translation of poems from a foreign language and vice versa, etc..

It should be mentioned that self-study is based on the scientific research, it serves to activate the reserve students'capacity, familiarizes them with research activities, creates and develops such important skills as information search, identification of the main idea, assessment of the stated material.

In our opinion,it is very importantto stimulate scientific search by students. Incentives to scientific work are not only the satisfaction that students receive from the creative thoughts, but also various forms of moral reward: awarding certificates, diplomas for the best work, awarding small commemorative prizes (books, albums), etc.

The most important and significant issues at self-studying are students' self-control and monitoring the process by the teacher.

Self-control is self-studying component, the means of regulation, correction, and improvement of the ways of its performance, and therefore we try to involve students themselves (through consultations with the teacher, classmates) in the process of control, in turn carrying out a systematic, continuous control of the progress and outcome of independent work, because self-made tasks, as well as any type of work, must be checked and evaluated by the teacher. Control, as well as moral encouragement, is an incentive for students, increases their interest in the performance of tasks, and allows them to achieve the desired results in the study of various topics in foreign language classes. Therefore, for the purpose of continuous feedback, constant control of independent work, we believe it is necessary to include students in the activities of self-control and cross check.

In our opinion, it is necessary to use self-study as often as possible in foreign language classes in higher education institutions. As it is mentioned in the literature, it is significantly important not only because it prepares students for self, independent study of subjects after the compulsory course of education, but also because of its motivational potentials: nothing inspires self-confidence, as the consciousness that the student has done the work him/herself, without someone's.

Based on our work experience, we can confidently state that the effectiveness of any self-study, independent work of students in foreign language classes in Higher education institutions depends mainly on the ability of the teacher to provide students with the necessary information about the goals, forms, types of self-study, independent activity and the order of its implementation. The student must have a clear understanding of what is required of him/her when performing this work. All these requirements should be set out in a special guidance that should be handed out to students before carrying out self-study assignments.

\section{CONCLUSIONS}

Thus, we can come to the conclusion that the process of acquiring a foreign language in university is not feasible withoutstreamlined organized self-study, both in class and out-of-class work. It requires students' efforts,studiousness and time. In the course of such activity, skills, desire for creative approach in educational, scientific and practical work of students are formed by means of personal searches and active 
interest to acquisition of knowledge, i.e. formation of the most important professional and personal competence of the future specialist is carried out. These are readiness and ability to continuous search of new relevant knowledge, competent realization of storage, processing of information and its effective application in practice during language communication.

\section{REFERENCE LIST}

1. Dorofeeva E.V. Didactic conditions and criteria for the development of students' creative potential in elective classes in the subjects of the humanitarian cycle: Diss. Cand of Ped.science / E.V. Dorofeeva; Kazan Federal University. - Kazan, 2006. - 312 p.

2. Zimnyaya I.A. Pedagogical Psychology for Higher Education / I.A. Zimnyaya. - M.: Logos, 2003. - 384 p.

3. Petrova L.A., Berestneva E.V., Brigadin A.A. Organization of students' self-study work according to Federal Educational Standard // Modern Issues of Science and Education. - 2015. - № 2-1. - URL: http://www.science-education.ru/ru/article/view?id=19211 